\title{
INICIATIVAS RENOVADORAS EN LOS CABILDOS PERUANOS A FINES DE LA EPOCA COLONIAL
}

\author{
POR \\ SERENA FERNANDEZ ALONSO \\ Centro de Estudios Históricos. \\ Departamento de Historia de América. Madrid
}

\section{LA REFORMA BORBÓNICA EN LA ADMINISTRACIÓN LOCAL. LOS INTENDENTES Y LOS CABILDOS}

En el último tercio del siglo XVIII, el gobierno local del Perú no presentaba sino un fiel reflejo de la irregular situación que afectaba a la sede del poder central. Cada cabeza de provincia se erigía como una pequeña Lima en la que se repetían las ienfermizas condiciones políticas" (1) de la capital: corrupción, intrigas, fraudes y ambiciones de todo tipo, se combinaban creando un ambiente irrespirable protestado ya largo tiempo antes de la visita general. Jorge Juan y Antonio de Ulloa daban cuenta de cómo los cabildos se habían convertido en campo de batalla entre distintos intereses en oposición:

... la tenacidad adquiere allí soberanía sobre toda la razón, y enfervorizados en la contienda que es propia donde un cuerpo político está dividido en bandos... crece la enemistad, y se fomentan las vejaciones... Así es que estas elecciones, cuyo fin debiera ser establecer gobierno y mantener en paz la república,

SigLAS UTILIZADAS:

AEA: Anuario de Estudios Americanos. Sevilla.

AGI: Archivo General de Indias. Sevilla.

AGS: Archivo General de Simancas.

BNP: Biblioteca Nacional del Perú. Lima.

HAHR: Hispanic American Historical Review. Durham.

RAH: Real Academia de la Historia. Madrid.

(1) Juan Browley Seminario, "El cabildo de Lima en la época virreinal". Anales del III Congreso Nacional de Historia del Perú 1963. Lima Perú, 1965. págs. 181-209. 
no son más que discordias en todo el discurso del año, adelantando la enemistad y los alborotos (2).

El desorden en la vida municipal peruana no difería gran cosa del que pudiera encontrarse en otras áreas virreinales del cono sur (3), pero adquiría allí una extraordinaria gravedad, al concurrir con otros males de la estructura económica y políticoadministrativa.

Los cabildos, una de las instituciones más puramente castellanas del mundo indiano, organismos corporativos en los que la población estuvo representada ante el gobierno y pudo emitir sus opiniones, demandas y quejas, se encontraban en franca decadencia. La venta de cargos, que se vio absolutamente disparada ante las urgencias financieras de la Corona durante el siglo XVII (4) dejaba ahora sentir sus perniciosos efectos. Los ayuntamientos se convirtieron en nidos de influencia de las élites locales, en núcleos desde los cuales podían hacer valer sus intereses y potenciar su poderío y ambiciones. A mediados del XVIII los cabildos habían perdido su tradicional autonomía, su prestigio, su independencia y libertad. Aunque habían llegado a convertirse en los órganos de expresión del poder criollo, con el tiempo, la intromisión de virreyes en el cabildo de Lima y de los corregidores en los provinciales, hicieron perder atractivo a los empleos de alcaldes y regidores que, cada vez con mas frecuencia, fueron quedándose vacantes (5). Cuando no, las elecciones se amañaban, quedando reducidas a un mero simulacro de lo que habían sido en épocas anteriores ya casi olvidadas. Una vez que los cargos capitulares mostraron no ser ambicionables económicamente o como catapulta de poder en el ámbito local, las varas se dejaban sin proveer, o accedían a ellas individuos de dudosa condición

(2) Jorge JuAn y Antonio de Ulloa, Noticias Secretas de América. Edición Facsimilar... Ediciones Turner. Madrid, s.f. vol. II. pág. 429.

(3) John LYNCH, "Intendants and Cabildos in the Viceroyalty of La Plata, 1782-1810". Hispanic American Historical Review. n 35, 3. Durham, 1955, págs. 337-362. Herbert PrIESTLEy, "Spanish Colonial Municipalities". California law Review, vol VII. Sep. 1919, págs. 397-416.

(4) Se ocupan, entre otros: Luis Navarro García, "Los Oficios vendibles en Nueva España durante la Guerra de Sucesión". AEA vol. XXXII. Sevilla, 1975, págs. 133-154. Fernando Muro Romero, "El beneficio de Oficios Públicos con jurisdicción en Indias. Notas sobre sus orígenes". AEA vol XXXV. Sevilla, 1978, págs. 1-67. Antonio Domínguez ORTIz, "Un Virreinato en venta". Mercurio Peruano. Vol. LXIX. Lima, 1965, págs. 43-51. Juan Antonio SuARDo, Diario de Lima. Introducción y Notas por Rubén Vargas Ugarte. Imprenta C. Vazquez L. Lima, 1935.

(5) John Fisher, "The Intendant System and the Cabildos of Peru, 1784 $1810^{\prime}$. HAHR vol. XLIX. n 3. Durhem, 1969, págs. 430-453. 
moral. Cada vez se hacía más difícil proveer los cargos municipales. Tal fue la situación que encontró José Antonio de Areche. La actividad municipal, donde existía, declinaba en forma irremisible manifestándose en:

... las reuniones cada vez menos frecuentes del cabildo, la reluctancia a proveer oficios municipales, la peculación e inadecuada administración de los fondos municipales, la ausencia de una expansión constructora municipal y la expansión de la incapacidad para decidir en materias urgentes de la administración pública (6).

A comienzos del 1782, el visitador Areche denunciaba ante la Corona los abusos cometidos por el virrey en las elecciones anuales de alcaldes y demás actos del ayuntamiento de Lima, privándolo de sus derechos y libertades (7). Aquel informe sintetizaba los interesantes descubrimientos efectuados por su comisionado en la averiguación de los desórdenes del cabildo, Benito de la Mata Linares, a quien habia nombrado poco antes como juez conservador de propios en un intento de organizar el caos existente en las finanzas municipales (8).

Con su tradicional convicción y vehemencia exponía Areche la obstaculización a que sometía el virrey todos sus intentos de reforma, ayudado por la Audiencia. Sus esfuerzos por recomponer los propios y arbitrios y por crear un archivo a cargo de un empleado, trabados por las dilaciones a que el virrey sometió los autos, le dieron ocasión para descargar sus iras contra el superior gobierno, evidenciando, una vez más, los graves conflictos de jurisdicción que se produjeron durante el desarrollo de la visita general, primero con su gestión, y más tarde con la de Escobedo:

... representa el Visitador que además de los perjuicios y daños que causa al público y a la Real Hacienda esta conducta tan extraña, violenta y despótica de los Virreyes, le privan el libre ejercicio de sus altas y justas comisiones, y las expone al ludibrio y censura dicho jefe y sus detestables aduladores (9).

(6) John Preston MOore, The Cabildo in Peru under the Hapsburgs; a study in the origins and powers of the town council in the Viceroyalty of Peru, 1530. 1700. Durham, 1954, pág. 265.

(7) Areche a Gálvez. Lima, 6 marzo 1782. AGI. Lima, 1090. N348.

(8) El Visitador Areche participa... que nombró a Benito de la Mata Linares... Lima, 6 marzo 1782. Ibidem. N383.

(9). Areche participa dificultades con el Virrey en el arreglo de los Propios y arbitrios... Lima, 12 marzo 1782. Ibidem. N389. 
La gravedad de los hechos haría que el programa reformista concediera una atención primordial a remediar los defectos del régimen municipal. El monarca expuso su confianza en que, tras los escasos logros de Areche, Escobedo venciera las dificultades con ayuda de las intendencias (10), que se orientaron a una revivificación de la actividad de los cabildos y a la recuperación e incremento de sus recursos financieros a través de un esquema de acción que abarcaba: "el nombramiento de unos individuos que hicieran cumplir las normas, la creación de un reglamento para su mejor funcionamiento, el establecimiento de la Junta Municipal de Propios, con una administración renovada, la creación de nuevos oficios y supresión de los innecesarios, y la fundación de archivos municipales...» (11).

El 12 de Julio de 1784, Escobedo se presentaba ante el cabildo de Lima para tomar posesión de su presidencia, que le correspondía como intendente de la ciudad (12). Aunque estaba convencido de que este cargo ahondaría las tensiones con el virrey, el nuevo visitador se mostró dispuesto a bregar con energía para lograr dinamizar la institución y devolverle sus libertades perdidas:

... y aunque en todos los Cabildos o Ayuntamientos habrá no poco que reformar, ninguno tendrá más que el de Lima, que en rentas, y circunstancias es Superior a los demás, pero como hoy se mira reducido a tres individuos de cortos medios, será imposible conseguir la reforma ni entablar cuanto se previene en la Instrucción... si no se formaliza antes este respetable Cuerpo, con el lustre que le corresponde... (13).

Ante la situación de vacío que vivía el ayuntamiento respecto a su composición, Escobedo inició su actividad por este punto, ya que, obviamente, lo primero que necesitaba para remozar el cabildo era que tal cabildo existiese.

Como primera medida, destituyó del cargo a Antonio Joseph Alvarez de Ron, regidor que había consagrado todo su esfuerzo

(10) Gálvez a Escobedo. Lima, 3 de diciembre 1785. RAH. Colección Mata Linares, t. CXII, fol. 183.

(11) M. ${ }^{a}$ Pilar Pérez CanTo, Lima en el siglo XVIII. Estudio socio-económico. Ediciones de la Universidad Autónoma. Madrid, 1985, pág. 40.

(12) El Ayuntamiento comunica al Visitador. Lima, 12 julio 1784. AGI. Lima,

(13) Informe de Escobedo sobre las Intendencias. Lima, 1 julio 1784. AGI. Lima, 117. 
a deshacer la reforma de los propios, planeada por Areche, mediante el fomento de intrigas entre sus homónimos, a los que convenció de la necesidad de resistir al visitador (14). A continuación, dispuso los medios necesarios para la provisión de vacantes mediante un recurso extraordinario consistente en designar a una serie de ciudadanos prominentes de Lima como regidores perpetuos y vitalicios, providencia con la que pretendía dotar a la institución de representantes honestos y de mérito, y prestigiarla así públicamente (15). Conociendo la mentalidad imperante en la sociedad virreinal, cabian pocas dudas respecto de que el mejor modo de atraer candidatos a las varas de alcalde era ofrecerles la posibilidad de codearse y establecer contacto con la élite capitalina.

Una vez más, Jorge Escobedo aparecía como el más capacitado para entender los caracteres del mundo virreinal. En 1784, a punto de poner en marcha las intendencias, el visitador encontró un clima más favorable por parte del cabildo hacia sus reformas, actitud muy distinta a la que hubo de enfrentar su antecesor y que, presumiblemente, era derivada de su reciente medida de provisión de regidores en el cuerpo municipal (16) bajo la plena aceptación del virrey. Escobedo manifestaba su optimismo ante los resultados de un recurso extraordinario que prometía los mayores éxitos:

... Lima queda hoy con general regocijo con un Ayuntamiento cual no ha tenido desde su erección, y estimulados todos de el honor y de la confianza de su elección, se muestran ansiosos de desempeñarla, y yo me prometo pueda por este medio salir esta capital de el desorden que ha malogrado sus propios... (17). N248

(14) Escobedo a Gálvez. Lima, 13 abril 1784. AGI. Audiencia de Lima, 1100.

(15) Escobedo a Croix. Lima 1 julio 1784 AGI. Lima, 1117 y Escobedo a Gálvez. Lima, 20 de agosto 1784. AGI. Audiencia de Lima, 1629 y 1098.

(16) FiSHER. [5], pág. 432. y 1098 .

(17) Escobedo a Gálvez. Lima, 20 agosto 1784. AGI. Audiencia de Lima, 1629

Los designados como regidores del cabildo de Lima fueron los siguientes: El señor conde de la Dehesa de Velayos, el conde de Monteblanco, el conde José González, caballero del hábito de Santiago y prior del Consulado. El marqués de Montemira, D. Felipe Sancho Dávila, D. Fernando de Roxas, el conde de Premio Real, D. Antonio de Elizalde, caballero del hábito de Santiago, D. Lorenso Encalada, alcalde ordinario de $2^{Q}$ voto y D. José Felix de Mendoza.

Como Alcalde de primer voto quedaba D. Andrés de Salazar y Maldonado.

Los miembros capitulares preexistentes que conservaron sus cargos fueron: Los Señores Maestres de Campo D. Juan Manuel de Buendia y Santa Cruz, marqués de Castellón, alférez Real de la ciudad y Alcalde Ordinario y D. Juan de Belsunce, D. José González Gutierrez, de la Orden de Santiago, Alcalde Ordinario; D. Juan José Vallejo, Alcalde Provincial de la Santa Hermandad y D. Manuel Negrón y Pacheco, Regidor Perpetuo y Depositario General de la Corte. 
El monarca confirmó en sus empleos a los diez sujetos designados como regidores de la ciudad (18), sancionando así las primeras intervenciones de Escobedo en la reforma del cabildo limeño, que quedó conformado por los miembros más selectos de la aristocracia criolla.

Simultáneamente a la acción desplegada en Lima por Jorge Escobedo, iba extendiéndose en provincias el régimen intendencial y, con él, la reforma de los respectivos regímenes municipales a cargo de los intendentes.

En prevención de que los conflictos experimentados con los prelados eclesiásticos pudieran repetirse con los representantes de los ayuntamientos locales, formó el Superintendente una normativa sobre el ceremonial que debía observarse en los actos públicos con los nuevos gobernadores provinciales (19). La Ordenanza regulaba, a lo largo de once artículos, el protocolo que mutuamente debían observar, salvaguardando sus privilegios respectivos y el brillo social de sus dignidades. Se pretendía, ante todo, evitar disputas y asegurar la concurrencia pacífica y disciplinada en el desempeño de sus funciones.

La segunda parte de la reforma debía abarcar la recuperación de las fuentes de provisión financiera municipal, sin las cuales resultaría imposible que el cabildo cumpliera con sus funciones públicas de reconstrucción urbana y cuidado de la "policía", e internas (pago de salarios, gastos de la institución, etc.). Por real orden de 15 de diciembre de 1733, Escobedo había recibido del Rey la facultad de dictar providencias sobre los propios y arbitrios tanto de Lima como del resto del virreinato. Sin embargo, y en orden a respetar las prerrogativas de los intendentes en aquel asunto, decidió el visitador inhibirse en lo respectivo a provincias y limitar su intervención a la jurisdicción de su intendencia (20).

En cumplimiento del artículo 23 de la Ordenanza de Intendentes, el visitador culminaba una de las reformas fallidas de Areche, la erección de un organismo centralizador de los ingresos municipales: la Contaduría General de Propios y Arbitrios. La tarea fue calificada por Escobedo de «bien pesada y escabrosa y, con espera de estudiar a fondo las circunstancias y de oir el

(18) Al Superintendente... aprobando y confirmando... 21 mayo 1785. AGI. Audiencia de Lima 619.

(19) Prevenciones de ceremonias, y cortesía recíproca de los señores intendentes con los cabildos seculares... Lima, 23 octubre 1784. RAH. Col. Mata Linares, tomo CXI. fols. 348-350 y Carta de Croix a Gálvez. Lima, 5 diciembre 1784. AGI. Audiencia de Lima, 646, N108.

(20) Escobedo a Croix. Lima, 1 julio 1784. AGI. Audiencia de Lima, 1117. 
dictamen del contador que dirigiera los ramos, optó por nombrar interinamente a Joseph Argote para el cargo, dotándole con 3.000 pesos (21). La medida resultaba innovadora, puesto que la ordenanza preveía que el ramo de propios fuese administrado por los oficiales reales de las cajas de Lima, a quienes Escobedo sabía excesivamente recargados de tareas, razón que le llevó a determinar la creación de una contaduría separada, en cuya decisión fue apoyado por la Junta Superior de Real Hacienda (22).

La Ordenanza de Intendentes sintetizaba, a lo largo de treinta artículos, los aspectos esenciales en que debían incidir los funcionarios reformistas para el arreglo de los propios y arbitrios del Reino. En primer lugar, prescribía la necesidad de adoptar un nuevo modelo de administración que pusiera fin a desórdenes y fraudes (arts. 23 a 27). Agrupaba normas para elaborar nuevos reglamentos (arts. 28 y 29) y disponía la creación de juntas municipales para el manejo de caudales y su contabilidad (arts. 30 a 49). Por último, organizaba el personal al servicio de las oficinas y los contadores y tesoreros ayudantes en la cobranza, que percibirian un $4 \%$ de los ingresos brutos del ramo (arts. 4548) (23).

Para establecer un funcionamiento homogéneo del ramo en todo el virreinato era preciso, ante todo, contar con una información exacta del estado de las fuentes de ingreso municipal, de la cual se pidió noticia a cada intendente.

Los propios y arbitrios eran «las heredades de propiedad de las grandes poblaciones, destinadas a los gastos públicos; administradas por el Cabildo, su arrendamiento se sacaba a remate" (24). Tales fondos comunales provenían de diversas fuentes, unas permanentes (impuestos, censos sobre capitales y propiedades, producto de fincas rústicas y urbanas, venta de cargos, etc.), que componian los ingresos habituales del ayuntamiento, de ahí su nombre de "propios», y otras accidentales, a las que se recurría temporalmente o como recurso extraordinario, por lo que se denominaban "arbitrios» o soluciones del cabildo para afrontar

(21) Ibidem

(22) Escobedo a Gálvez. Lima, 15 diciembre 1784. AGI. Audiencia de Lima, 1104. N486.

(23) Real Ordenanza para el establecimiento e Instrucción de Intendentes. El Pardo, 28 enero 1782. RAH. Mata Linares, tomo CX. fols. 37 y ss. Alfredo MORENo CEBRIAN, "Un arqueo a la hacienda municipal limeña a fines del siglo XVIII". Revista de Indias. $\mathrm{n}^{9}$ 165-166. Madrid, 1981, pags. 449-540.

(24) Jose M. Valega El Virreinato del Perú. Historia crítica de la época colonial en todos sus aspectos. Ed. Cultura Eclesiástica. Lima, 1939, pág. 463. 
gastos específicos, y que podían variar en función de las coyunturas (sobrantes de algún ramo, impuestos que se derivaban a sus fines, como la sisa, el mojonazgo, etc., donativos...).

La revisión de los mismos mostró una situación generalizada de déficit. Fuera de fraudes internos y malversación de fondos como elemento cotidiano de la administración, en todas partes, los gastos excedían con mucho a unos ingresos de por sí poco cuantiosos que se despilfarraban con una absoluta falta de previsión. El recibimiento de los virreyes, la semana santa, las onomásticas de la familia real, constituían las principales ocasiones para organizar celebraciones, fiestas y ceremonias muy costosas en las que los cabildantes, ansiosos por exteriorizar su poderío y prestigio, derrochaban el caudal de las arcas públicas para financiar banquetes, fuegos artificiales, bailes, corridas de toros y un largo etcétera (25).

A la hora de la verdad, llegado el momento de atender necesidades perentorias de reconstrucción o saneamiento urbano, el cabildo se encontraba arruinado. Resultaba evidente la necesidad de buscar nuevas fuentes de ingreso, reglamentar el manejo del metálico y restringir los gastos. Hacia estas tres metas se encaminó la reforma del intendente Escobedo en Lima.

Con respecto a la creación de arbitrios, se sugirieron distintas posibilidades: imponer una tasa sobre los carros que transportaban mercancías entre la capital y El Callao, aumentar tasas ya existentes, incorporar el mojonazgo, cobrar $1 / 2$ real por cabeza de cerdo de los conducidos por Lima para pagar los deterioros de las calles, gravar más rígidamente el juego... (26).

Escobedo era consciente de la deplorable situación económica del cabildo de la ciudad, como también de la imposibilidad de aumentar cualquier impuesto a la población:

... los propios del Cabildo están en el más lastimoso atraso... no puede echarse mano de ellos... y se hacía inevitable buscar un arbitrio extraordinario que sin tocar en los inconvenientes del primero, fuese en realidad una pensión suave que el público pagara sin repugnancia, ni necesidad de exigírsela (27).

(25) Juan Bromley Seminario, "Recibimiento de Virreyes en Lima". Revista Histórica, vol. XX. n 10. Lima, 1953, págs. 32-74. y "Fiestas Caballerescas, Populares y Religiosas en la Lima virreinal" Revista Histórica, vol. XXXI. $\mathrm{n}^{2}$ 21. Lima, 1964 , págs. $200-220$.

(26) MOORE, The Cabildo in Peru under the Bourbons A study in the decline and resurgence of local government in the Audiencia of Lima. 1700-1824. Duke University Press. Durham, 1966, pág. 157. N514.

(27) Escobedo a Gálvez. Lima, 5 julio 1784. AGI. Audiencia de Lima, 1101. 
Así pues, basándose en el impuesto llamado bodegaje que satisfacían los navieros chilenos por depositar el trigo que vendían en Lima en las bodegas del puerto de El Callao (28), así como en los abusos introducidos por los compradores y transportistas capitalinos, el visitador optó por cobrar a éstos un real por fanega de trigo, bajo la condición de que no aumentarían el precio de venta a los panaderos de la ciudad. El producto anual de aquella nueva imposición se calculó en 28.658 pesos, cantidad que, aun siendo inferior a lo necesario para atender a los gastos de policía de Lima, constituía una preciada ayuda para el inicio de algunas obras.

Asimismo, dispuso Escobedo, a instancias del cabildo, gravar con $11 / 2$ ó 2 reales la arroba de ají, producto que comerciaba masivamente el puerto de Ica y que, finalmente, fue reducido a 1 real por arroba, incorporando, además, a los propios, los gastos de vivienda y sustento del subdelegado de aquel partido, los cuales serían suprimidos años después (29). Como recurso temporal, Escobedo permitió que los fondos del ramo de sisa se destinaran a la reconstrucción de los puentes y canales de provisión de agua de la ciudad (30).

En un segundo orden de actividad, encontramos la de tipo legal, la emisión de normativas que regulasen el manejo y empleo de los fondos públicos, de acuerdo a las prescripciones de la ordenanza intendencial. Una vez recopilada la información general sobre el estado y cuantía de los capitales municipales, los intendentes debían redactar instrucciones para su administración.

Escobedo era el más experto en tales menesteres. Su Ordenanza estuvo dispuesta en mayo de 1785 (31) e iba encaminada a resolver el tercer aspecto de la reforma que señalamos previamente: la restricción de gastos superfluos. El ingreso, proveniente casi en exclusiva del mojonazgo (impuesto sobre vinos y aguardientes), era irregular, y ascendía a unos 36.380 pesos al año. Los gastos en salarios, censos y fiestas de dotación, sumaban unos 20.600 pesos anuales, sin contar los extraordinarios (compostura

(28) Demetrio Ramos, "Trigo chileno, navieros del Callao y hacendados limenos entre la crisis agrícola del s. XVII y la comercial de la primera mitad del XVIII". Revista de Indias, Madrid, 1967, págs. 93-115.

(29) Escobedo a Sonora. AGI. Lima, 1113. N841 y Real Cédula sobre arreglo de propios y arbitrios... Aranjuez, 14 abril 1788. BNP. Manuscritos. C 2839.

(30) MOORE. [26], págs. 157-158.

(31) Escobedo acompaña una copia de los reglamentos que ha formado... para los gastos de los Propios del Cabildo... Lima, 20 mayo 1785. AGI. Lima, 1104. N487. 
de cañerías, pilas, puentes, tajamares del río y otras obras públicas). Resultaba, por tanto, un sobrante de 15.800 pesos para atender a los elevados gastos de mantenimiento urbano. Fuera de ellos se encontraban, además, los de las

entradas de los virreyes que han sido una de las principales causas de el atraso, y desorden de los Propios... porque nunca pueden las rentas alcanzar a cubrirlos... (32).

Sólo en ese concepto, se gastaron entre 1776 y 1784, 135.157 pesos, 63.438 en recibir a Guirior, 25.600 en la recepción de Jáuregui y 46.119 en la de Croix, gastos excesivos que desembocaron en la "dolorosa constitución de los Propios» que encontró Escobedo (33). Su primera medida consistió en reducir sueldos y aplicar una política de economías, gracias a lo cual consiguió un ahorro anual de 4.000 pesos, contando para ello con el beneplácito del ayuntamiento, aspecto muy importante, teniendo en cuenta la dura oposición que manifestó la institución ante las reformas de su antecesor.

"Todo se ha hecho con particular complacencia del Cabildo, y sin los disgustos que anteriormente hubo por solo el amago de la reforma...." (34).

El Reglamento constaba de ventidos artículos que regulaban la reunión semanal de los cabildos ordinarios y de la Junta Municipal de Propios que fijaba la Ordenanza de Intendencias para controlar los fondos municipales y las cajas de comunidad. De ambas reuniones debía darse cuenta, posteriormente, a la Intendencia $\left(\operatorname{art}^{9} .1^{9}\right)(35)$. Salvo el juez de aguas, el procurador general y los dos abogados, los capitulares podrían asistir a las reuniones por turnos alternativos $\left(\operatorname{art}^{0} 2^{2}\right)$, salvo en caso de tener que tratar asuntos de urgencia o especial gravedad $\left(\operatorname{art}^{\circ} 3^{\circ}\right)$. Se prescribían, asimismo, los procedimientos de votación ( $\operatorname{art}^{\mathbf{9}} 4^{\mathbf{9}}$ ), elaboración de actas $\left(\operatorname{art}^{9} 5^{2}\right)$, vestuario, funciones del personal (arts. 7 y 8), formación de archivo y servicio de escribanos públicos (arts. 9 y 10), vigilancia de delincuentes en las vías y

(32) Ibídem.

(33) Ibidem.

(34) Ibidem.

(35) Reglamento que deberá observar y cuidar... en los artículos que comprende el Muy Ilustre Cabildo de la Ciudad de Lima. Lima, 15 junio 1785. AGI. Lima, 1101, N515. 
locales públicos $\left(\operatorname{art}^{\mathrm{Q}} 12^{\mathrm{Q}}\right)$, inspección de calidad alimentaria y abasto público (arts. 13 y 16-18), condiciones de apertura de locales (arts. 14 y 15) y control de precios al consumo (art. 19).

El reglamento fue aprobado por real orden de 12 de abril de 1786 (36). Dos años más tarde, otra real orden fechada en 3 de abril, sancionaba plenamente el plan formado por Escobedo para limitar los gastos en los actos de recibimiento de virreyes a 12.000 pesos. Con ellos habrían de costearse la cama con colgadura de damasco y sábanas de tisú, los vasos de plata, la carroza y el tiro de caballos, los manteles, comidas y refrescos, la música para dos noches, la iluminación del palacio y los balcones del cabildo, la limpieza de arañas y faroles, las propinas a los guardias de tropa y alabarderos, porteros de la audiencia y criados de librea, así como gastos menores en general (37).

Si bien es cierto que, globalmente, el cabildo limeño se mostró satisfecho y agradecido con las medidas implementadas por Escobedo para la reforma de la economía municipal, no lo es menos que la ordenanza de intendentes dio lugar a algunos conflictos de jurisdicción que afectaron directamente a la relación entre el Virrey y los nuevos gobernadores provinciales.

Señalamos anteriormente cómo el superior gobierno, durante décadas, se había excedido en su intervención en la actividad de los cabildantes, hasta el punto de anular la independencia y capacidad decisoria de los Ayuntamientos. La Ordenanza de Intendentes tuvo la peculiaridad de introducir un cambio significativo en el statu quo de la autoridad virreinal: la prerrogativa de confirmar las elecciones concejiles fue traspasada a los intendentes en virtud del artículo $8^{\circ}$ de la nueva normativa. Tal disposición derogaba la ley, 3.10 de la Recopilación de Leyes de Indias y confirmaba el punto 33 de la Instrucción privada dada al virrey Croix para su gobierno, según la cual, debía abstenerse de nombrar alcaldes ordinarios y de mezclarse en dichas elecciones más que para aprobarlas. La reforma pretendía, como dijimos, devolver a los cabildos su autonomía, liberándoles de la dependencia a que los sometían los virreyes, dinamizando y potenciando sus libertades.

Haremos referencia al caso de Lima, puesto que nuestro análisis viene ocupándose de la que fue la acción directa del

(36) Indice de las Reales Ordenes recibidas por la vía de Cartagena. Lima, 2 octubre 1786. AGI. Lima, 1113. N768.

(37) Plan de gastos fijos e inalterables que han de costear los propios del cabildo en las entradas de los virreyes. Lima, 9 mayo 1787. AGI. Lima, 609. 
intendente Escobedo. Pues bien, en 1787, presentaba éste una queja ante el monarca por las continuas injerencias del virrey Teodoro de Croix en la actividad del cabildo limeño. Sus expresiones no dejaban lugar a dudas sobre el alcance y gravedad de tal actitud:

... todo lo que en ella se refiere es muy opuesto á estas soberanas disposiciones... á pesar de todas ellas el virrey pretende mezclarse en las elecciones... se vuelve á abrir la puerta para el abuso y se trastorna enteramente lo dispuesto en el plan de Intendencias desde cuyo establecimiento ha gozado el cabildo de Lima de libertad que nunca tuvo... (38)

La razón del empeño de Croix en que las elecciones a las alcaldías ordinarias se sometiesen a su permiso previo (39) no era otra que la consabida pugna por sostener sus privilegios de autoridad frente a los de la superintendencia, postura que Escobedo atribuía a los perniciosos influjos de gentes allegadas al virrey que le «displicentan cada día más».

La pretensión virreinal de aprobar o revocar las elecciones municipales era, en opinión de Escobedo, inaceptable, en razón de que un hecho asi revertiría en descrédito de los intendentes. Sí convenía, sin embargo, en la posibilidad de que el virrey, en caso necesario o si tuviera noticia del demérito de algún candidato, comunicara reservadamente al intendente los perjuicios que podrían derivarse de su elección. El virrey optó por demostrar su descontento al cabildo públicamente, negándose a salir a los paseos oficiales, delegando su representación en el regente de la audiencia, actitud que desairaba tanto al superintendente como a los alcaldes del cabildo y que sorprendía a la población. Estos hechos, y el anuncio del virrey de que presentaría sus quejas al Rey fueron las razones que empujaron al intendente de Lima a informar del asunto. Las frases de Escobedo que incluimos a continuación dan prueba de la trascendencia que las cuestiones de protocolo y ceremonia tenían en la Lima del siglo XVIII, así

(38) El Superintendente informa lo ocurrido con el Virrey sobre las elecciones de alcaldes... Lima, 5 enero 1787. AGI. Lima, 1113. N829.

(39) Indice de las representaciones del virrey Croix a Sonora. Lima, 5 enero 1787. AGS. Secretaría de Guerra.

Curiosa y paradójicamente, en 1789, encontramos al virrey Croix presentando una denuncia ante el Ministro Valdés, basada en que los intendentes habían atropellado la libertad de los cabildos mediante una continua intrusión en sus asuntos: Croix a Valdés. Lima, 16 mayo 1789. AGI. Lima, Indiferente General, 1714. 
como de la dimensión alcanzada por la enemistad personal del virrey con el superintendente:

...«todo el fruto que he sacado de unas demonstraciones tan atentas ha sido quedarse siempre el Virrey resentido y repetirme el día de año nuevo el sonrojo que ya en el del año pasado experimenté de no merecerle ni aun por pura política un recado de convite para el refresco que en aquella noche y la de Reyes tiene, y a que convida en su caballerizo a todos los ministros, inspector y no sé si algunos más... y de todos modos cumplía con insinuarmelo, pero no le hé merecido... me diga una palabra, ni emvie un dulce, habiendolos repartido a alguna otra casa donde no concurren los motivos que en la mía por el carácter de mis empleos» (40).

Tras unas quejas que, incluso entonces, podían parecer ingenuas, subyacía un sordo conflicto cuyos efectos políticos podían ser irreparables:

... me obligaron a manifestar unos sentimientos que en otras circunstancias miraría con desprecio, y referiría con rubor, pero aunque parezcan pueriles son un testimonio bien irrefragable de lo que pasa, y sufro, y de lo que todo el pueblo nota...

... Todos imaginarán más desunión y desavenencia de la que en realidad hay (41).

Una vez más, la falta de atención mostrada por el gobierno central a las advertencias que en 1783 hiciera Escobedo sobre los graves efectos de la ambigüedad, se dejaban sentir trabando cuantas medidas pudieran aplicarse en la reforma de una sociedad profundamente reaccionaria.

La relación entre los intendentes y los representantes del poder local eclesiástico y secular, así como con los organismos corporativos provinciales, constituye una prueba indiscutible de las contradicciones internas que afectaban al proyecto reformista y, más concretamente, a la Ordenanza en la que se basaba la reestructuración político-administrativa.

(40) Escobedo a Sonora. Lima, 5 enero 1787. AGI. Lima, 1113. N829.

(41) Ibidem. El clima de rechazo creado por el Virrey contrastaba con los esfuerzos del Superintendente por conservar la armonía. Escobedo se abstuvo de concurrir a los paseos públicos para que el virrey no viese que con su presencia pretendía rebajar su dignidad. Véase: Alonso Valencla Llano, "El chisme y el escándalo en la sociedad colonial". Estudios Sociales. $n^{2} 3$. Antioquía Colombia, 1988, págs. 33-48. 
A pesar de las múltiples controversias a que dio lugar su establecimiento, debe aceptarse que los intendentes ejercieron una importante labor en la reafirmación de los cabildos como órganos activos de representación local. Culminada la fase de reactivación interna y dotación de mayores y más cuantiosas fuentes de ingreso, los ayuntamientos estuvieron en disposición de ejercer sus obligaciones municipales, las cuales se habían sintetizado a los intendentes a lo largo de los artículos 53 a 70 de la Ordenanza, relativos al ramo llamado de Policía (42).

\section{EFECTOS DE LAS REFORMAS DE ESCOBEDO EN LOS CABILDOS}

El fracaso de las medidas implementadas contra la delincuencia en Lima no debe oscurecer los importantes logros del intendente Jorge Escobedo como promotor de la reforma del cabildo capitalino, la cual sirvió como modelo para la dinamización simultánea de los demás ayuntamientos virreinales liderada por los Intendentes. La aplicación de la Ordenanza intendencial permitió la reconstrucción interna de los cabildos y de las fuentes de que se nutrían sus recursos, hecho que redundó en la recuperación de su capacidad para dirigir los asuntos municipales y asumir las tareas de representación popular. El régimen de las Intendencias constituyó el cauce a través del cual resucitaron las instituciones de gobierno local del virreinato peruano (43).

La "policía», obras públicas, higiene, finanzas y justicia como actividades de primordial atención por los municipios, pudieron superar una fase de incuria administrativa que, lentamente, les había llevado a la postración.

La injerencia arbitraria de virreyes y gobernadores dejó paso a la acción de los intendentes quienes, inyectando fuertes dosis de energía y dedicación, alentaron a los representantes provinciales a retomar las riendas del gobierno local. Un cierto sector de la historiografía americanista ha objetado con rotundidad la intervención de los intendentes, que supuso una grave pérdida de terreno para los cabildos, los cuales se habrían visto arrollados por el intrusismo de aquéllos en asuntos cuya dirección les pertenecía en exclusiva, privativamente: "Como es evidente, el inme-

(42) Real Ordenanza para el establecimiento e instrucción de Intendentes. El Pardo, 28 enero 1782. RAH. Colección Mata Linares, tomo CX. fols. 31 y ss.

(43) FISHER, BROWN Y ACEVEDo son los principales sustentadores de esta tesis que valora positivamente la gestión del régimen intendencial hacia los cabildos. 
diato efecto de la intendencia en Lima fue un cercenamiento de la autoridad y prestigio de los regidores y alcaldes" (44). No podemos por menos de disentir con tal planteamiento para, una vez matizado, adherirnos a quienes, como Fisher, afirman que "la idea de que los Intendentes los oprimieron es un mito" (45). A nuestro juicio, intervención no conlleva, indefectiblemente, opresión. Es indudable que los nuevos gobernadores provinciales tomaron parte activa, sobre todo al principio, en organizar y reorientar las elecciones concejiles y en encauzar las manifestaciones del poder local de acuerdo a los lineamientos marcados por la reforma. Pero debe tenerse en cuenta, por un lado, la lamentable parálisis que sufrían las instituciones y el desenvolvimiento posterior de las mismas. En suma ¿cabe pensar en un atropello de derechos y libertades cuando éstas y aquéllos no existían? ¿Puede hablarse de extralimitación en el ejercicio de la autoridad cuando ésta se encuentra refrendada juridicamente por una reglamentación legal? Más aún, ¿se trató de una medida coyuntural ineludible en razón de unas circunstancias extremas, o de una política subyugante con carácter permanente?

Durante los primeros momentos de la acción de los intendentes, la estructura de poder local se hallaba profundamente deteriorada. Donde no se habían desintegrado, los cabildos aparecían como viejas instituciones momificadas, carentes de capacidad alguna para regirse políticamente y encarar con eficacia el reflotamiento de sus recursos financieros.

El rescate de su identidad corporativa y su operatividad económica constituyó uno de los desafíos a los que los intendentes supieron dar respuesta, pero exigió que accionaran el mecanismo desde dentro, rehaciendo, más que reformando, y con las facultades que a este fin les otorgaron las Ordenanzas.

Nuestro análisis ha hecho expresa referencia a la intervención del intendente Escobedo en el cabildo de Lima. La repoblación interna a que procedió, recurriendo a un sistema extraordinario, no constituyó la norma posterior en la renovación de representantes capitulares. Como en otras provincias, las elecciones posteriores discurrieron en el marco de la libertad de los ayunta-

(44) MOORE [26], pág. 159-160. En la misma línea criticista se encuentran Lynch y Comadrán. El primero de ellos considera (en su artículo "Intendants and Cabildos...") que las intendencias no promovieron cambios significativos o sustanciales en el grado de autoridad de los Ayuntamientos, mientras que, el segundo, afirma ("La Real Ordenanza de Intendentes...") que el nuevo régimen supuso un retraso para la normal evolución de la actividad municipal.

(45) FiSHeR [5], pág. 452. 
mientos en el ejercicio de sus prerrogativas y en su respetuosa aceptación y frecuente defensa por parte de los intendentes (46).

Sin que nos sea dable negar que las Intendencias no pudieron erradicar en su totalidad los defectos de las instituciones del gobierno local del virreinato, debemos admitir que les devolvieron su prestigio y restauraron plenamente su aptitud para el desempeño de sus cometidos. Los Ayuntamientos regionales expresaron, en más de una ocasión, su agradecimiento a los intendentes por la labor realizada (47), hecho que avala nuestra argumentación y refuta, a la vez, las tesis que sobre el avasallamiento por parte de los nuevos funcionarios sostienen algunos autores. El control inicial por parte de los intendentes constituyó una solución de urgencia abandonada apenas los cabildos volvieron a dar muestras de haberse sobrepuesto al infarto de su operatividad. En conjunto, y aunque serian necesarias exhortaciones posteriores a la perseverancia en el dinamismo insuflado por los gobernadores regionales (48), las corporaciones municipales reasumieron en breve tiempo sus responsabilidades en la administración pública, repudiando las extorsiones del poder virreinal y reivindicando, paulatinamente, la extensión de sus derechos y libertades (49). La aspiración de los cabildantes por una mayor intervención en las áreas de influencia de los Intendentes, primero, y por reemplazarles en el ejercicio de la autoridad en el gobierno municipal, después, pone de manifiesto la eficacia de aquéllos en la tarea de reanimación de las instituciones locales. Los cabildos se hallaban fortalecidos y en plena disposición para acaparar en exclusiva el ejercicio del poder. Los intendentes asistían al despertar de la conciencia criolla representada en las instituciones municipales que habían reformado, hecho paradójico del que emergerían renovados y agravados conflictos (50). La actitud de los cabildos «era sintomática del deseo general de los criollos por obtener

(46) Idem. Gobierno y Sociedad en el Perú colonial: El Régimen de las Intendencias. 1784-1814. Pontificia Universidad Católica del Perú. Fondo Editorial, Lima, 1981, pág. 202.

(47) El Cabildo al Intendente de Lima. Lima. 6 abril 1786. AGI. Lima, 802.

(48) Oficio del intendente Escobedo al Cabildo de Lima. Lima, 14 diciembre 1785. AGI. Lima, 802. 443.

(49) LYNCH [3], págs. 356-357 y MOORE [26], págs. 160-161 y FisHER [5], pág.

(50) Héctor Ramón LoBos, "Los Cabildos y la dinámica revolucionaria en el Río de la Plata. Un esfuerzo de comprensión a partir del caso cordobés". AEA. vol. XLVI. Sevilla, 1989, págs. 383-407 y Bernard LAVALLE, "Del espíritu colonial a la reivindicación criolla o los albores del criollismo peruano". Histórica, vol. II. $n^{9}$ 1. Lima, 1978, págs. 39-61. 
una mayor participación en su propio gobierno» (51). La reforma de intendentes en el régimen municipal apenas tuvo tiempo de ser saboreada desde la Corte. Sus brillantes resultados se volvían en su contra, oponiéndose a los principios en los que el proyecto se había basado.

La sujeción de los grupos de poder locales, la destrucción de los vínculos entre las élites, el despliegue de una estructura que mejorase el gobierno y fortaleciese el control sobre los rebeldes vasallos americanos, apoyaturas esenciales del Reformismo Borbónico, terminaron quebrando irremisiblemente. Mientras el gobierno peninsular ponía proa hacia un mayor conservadurismo en la orientación política a partir de 1788, se generaban en territorio virreinal enérgicas iniciativas en favor de una extensión de las libertades. El proceso queda fuera de los límites cronológicos de nuestra investigación, razón por la que tan sólo se menciona, en orden a esbozar el desenvolvimiento de la reforma municipal una vez culminada la Visita General del Virreinato.

Durante la última década del siglo XVIII, representantes del cabildo limeño de la talla de José Baquíjano y Carrillo y Tadeo Bravo del Rivero, demandaron ante la Corona mayores privilegios para su corporación y la ampliación de la representatividad de los criollos en las instituciones del gobierno virreinal. Consecuencia directa de aquellas instancias serían la supresión en 1802 de la Contaduría General de Propios y Arbitrios que había establecido el superintendente Escobedo y la restitución al Cabildo del control sobre aquellos fondos. Quedaban así barridas dos de las principales reformas implementadas por el régimen intendencial (52). Los cabildos provinciales no tardarían en seguir el ejemplo de la corporación municipal limeña.

Los efectos de la reforma de Escobedo y de su equipo de colaboradores provinciales habían resultado, esta vez, altamente contradictorios. Huelga decir que respondían a las vacilaciones y ambigüedades del proyecto borbónico, y no a una equivocada gestión por parte de los funcionarios comisionados para su aplicación, los cuales se mostraron más decididos y eficaces en la puesta en marcha del sistema intendencial que en cualquier otra de las reformas efectuadas hasta entonces. Dejando a un lado las derivaciones ulteriores de los regímenes municipales peruanos,

(51) John LyNCH, Administración Colonial Española. 1782-1810. El sistema de Intendencias en el virreinato del Rio de la Plata... Eudeba Editores. Buenos Aires, 1962, pág. 266.

(52) FISHER [47], págs. 208 y ss. 
la conclusión sobre la actividad de los intendentes en el gobierno local del virreinato es que estuvieron a la altura de la difícil misión que se les encomendó, a la que dieron cumplimiento con una prudencia no exenta de energía y auténticamente encomiable. En sólo cuatro años y gracias a ellos, las instituciones municipales recuperaron su organización interna, sus fuentes de recursos y su capacidad para ocuparse de las tareas de la administración pública. 